\section{DRIED FOODS}

A

$\mathrm{T}$ a joint meeting of the newly formed Nutrition Society and of the Food Group of the Society of Chemical Industry, held in the Great Hall of the British Medical Association on July 25, a series of papers was devoted to giving an account of the results that have recently been achieved in improving the quality of dried foods. The meeting was private, several hundred members being present. In the morning the chair was taken by Sir Edward Appleton, secretary of the Department of Scientific and Industrial Research, and in the afternoon by Dr. H. E. Cox, chairman of the Food Group, deputizing for Dr. L. H. Lampitt of Messrs. J. Lyons and Co. Ltd., who was unfortunately prevented from being present.

In introducing the morning session, Sir Edward Appleton told the meeting how the Food Investigation Board of his Department, under the chairmanship of Sir Joseph Barcroft, had realized the tremendous importance which must attach to the utmost economy in transport of foodstuffs, particularly overseas transport, under war conditions, and had been concentrating for some time on dehydration. It has been estimated that in peace-time we imported every year as much as three million tons of water with our foodstuffs.

He thought that history would show that science had made tremendous contributions in the present War and that these contributions had been made largely by anticipating needs. It was quite possible that the work that had now been done on dried foods would be far from the least of these. It had been realized that the nutritional quality of dried foods was of critical importance and the Medical Research Council had collaborated on this aspect at the Dunn Nutritional Laboratory, Cambridge. The work had been organized by Mr. Eric Barnard, director of food investigation, and carried out chiefly at Cambridge under the scientific leadership of Dr. Franklin Kidd, of the Low Temperature Research Station.

In an introductory paper covering all commodities, Dr. Franklin Kidd pointed out that fundamentally no new discoveries had been made but that, nevertheless, by bringing together what was already known in other branches of the food industry and applying the results to dehydration, it could now be said, in general, that the nutritivo quality and palatability of dried foods such as meat, fish, milk, eggs and vegetables would be equal to that of those preserved by the established processes of canning and refrigeration. The main principles which had in general to be observed were to destroy the enzymes by a short heat treatment before drying; to maintain a low water content in the dried product during storage and distribution, which can only be done by shielding it from contact with air; to exclude oxygen or retard oxidative changes by the use of antioxidants and avoidance of contamination with traces of metal; to avoid temperatures during drying above a certain limit which can easily be determined for any product, but nevertheless to dry as quickly as possible; to avoid temperatures during drying at which bacteria will flourish; and, lastly, to select the best material as regards flavour, appearance and nutritive value and to treat it with scrupulous cleanliness during the manufacturing operations. We could not hope for good dried foods if drying were used as a means of disposing of fresh food which had deteriorated too far for distribution in the fresh condition.

As an illustration of the economy in space and weight Dr. Kidd stated that the requirement for a full normal dietary consisting of flour, biscuits, cereals, potatoes, vegetables, pulses, meats, soups, fats, sugar, eggs, fish and milk, in the requisite proportions and including packaging, would reduce to a quarter of its weight and volume.

Dr. E. C. Bate-Smith, Miss E. M. Cruickshank and Dr. J. G. Sharp described fully the process for the drying of meat in the form of a mince which, for storage and distribution, is compressed into blocks and packed in air-tight cans. It had been found that the digestibility of this meat was unimpaired and that when the drying was carried out between the temperatures specified $\left(60^{\circ}\right.$ to $80^{\circ} \mathrm{C}$.) there was little or no loss of vitamin $B_{1}$ during drying, nor was there any loss of nicotinic acid or riboflavin. Vitamin $B_{1}$ is also retained during storage, but the retention of nicotinic acid and riboflavin has not yet been investigated. The fat content of the dried meat was 30-45 per cent on a dry weight basis.

As regards egg it had been found that little denaturation and coagulation of the protein occurred in spray-drying if the temperature of drying, as measured by the outlet air temperature, did not exceed $70^{\circ}$. No loss of vitamins A and D was observed during the drying. There was a loss of 30 per cent of the vitamin $B_{1}$.

What was particularly aimed at both with regard to meat and egg was the full retention of the characteristic flavour, odour, colour and appearance of the fresh food. Quality grading was therefore being carried out by a system of tasting panels which have proved unexpectedly simple in operation and capable of repeating judgments with consistency and accuracy. Surveys had also been carried out to ascertain the sensitivity of the average consumer to unit differences on panel scoring and, for immediate purposes, the level of what may be described as public acceptance has been ascertained. If dried meat and dried egg are protected from the access of air and the uptake of water, they can be stored for long periods without loss of quality.

Dr. G. A. Reay of the Torry Research Station described the roller-drying of minced fillets of raw cod, haddock and whiting in about a quarter of a minute to a water content of 8 per cent. A better product was produced by mincing pre-cooked fish and drying on trays between temperature limits which have been determined. With both fish and meat it is preferable to mince after cooking, that is, following the natural shrinkage which occurs after coagulation has taken place.

Dr. R. J. L. Allen, Dr. J. Barker and Dr. L. W. Mapson described in detail the process of drying cabbage, carrot and potato. Each of these vegetables must be given a heat treatment ('scalding') before being dried and, for the protection of the ascorbic acid from oxidation, the addition of a small quantity of sulphite to the scalding liquor is very beneficial. The reconstituted and cooked dried cabbage and potato should contain at least 35 per cent of the ascorbic acid of the raw vegetable, which is as much as, or more than, is retained when fresh vegestables are cooked. There is practically no loss of carotene during scalding, drying or reconstitution and cooking.

While storage of the dried product in air, but at low water content, is possible for reasonable periods with cabbage and potato, carrot should always be stored in an atmosphere free of oxygen owing to the destruction of carotene by the axygen.

In winding up the sessions, Sir Joseph Barcroft 
spoke briefly of the possible effect of dehydrated foods on the trend of national life and policy. It was clear, he thought, that dehydration plant would have to be situated where the food was produced and that we must realize that, with the possible exceptions of vegetables and milk, the dried foods we obtained would, for the most part, be dried overseas. If dried foods had a future it would obviously have profound reactions on the organization of transport and distribution. It was well worth facing this problem now because it would be much more easily dealt with when industries largely wrecked could be reconstituted on new lines than when normal industries would have to be remodelled at considerable loss. In particular, he wanted British agriculture to take advantage of dehydration as a means of getting the maximum production in its natural season. If British agriculture seized its opportunity, he believed the producer of good food would benefit, although the producer of inferior products might rightly regard dehydration as something of a menace.

The quality of dried foods prepared by the methods now being employed was not only high but it was ascertainedly so by assay for palatability, vitamin content, etc., and hence could be guaranteed. This he considered most important from the point of view of efforts to raise the nutritional status of the population as a whole. It was already clear that the price of dried foods would not exceed that of fresh foods and might be less owing to economies in cost of distribution and saving of wastage.

While it was impossible in so large a meeting for discussion to go into any detail, several interesting points were raised. Mr. Nevill Wright and several other speakers stressed the need of urgency and asked for information as to what steps were being taken to push forward with production of dried meat and vegetables. The question was raised as to what were the most suitable types of plant for drying different foods and, in particular, stress was laid on the importance of the efficiency of drying in terms of fuel consumption.

In reply to these points Dr. Kidd and Dr. BateSmith stated that stress had intentionally been laid on the importance of the pre- and post-drying treatment of the products and of the temperature limits during drying rather than on the exact specifications of the plant to be used. It was felt, in general, that while some adaptations might be necessary, the drying of meat and vegetables would not necessarily call for completely new types of plant design. In terms of the value of the material the cost of drying was negligible.

Dr. Colgate wanted to know whether it was possible to dry eggs without losing their beating quality, which contributed much to the value of the egg in the baking trade. He had not found even the best spray-dried egg equal to frozen egg pulp. Dr. BateSmith said that even egg dried out in a vacuum in a frozen condition had lost its aerating power to about the same extent as the spray-dried egg powder. However, this loss of beating quality could easily be overcome by the simple device of beating at an elevated temperature, for example, $40^{\circ}$. Even really poor spray-dried egg powder would give good aeration if the temperature of beating was raised to $50^{\circ}$ or $55^{\circ}$.

Squadron Leader Macrae described experiences in the Royal Air Force. From every point of view these new dried foods were what was wanted. The men liked them and trials had shown that they got more vitamin C from dried cabbage than from fresh. This was due to the fact that the cabbage was dried in such a way as to preserve vitamin $\mathrm{C}$ while at the same time destroying enzymes which caused the loss of vitamin $\mathrm{C}$ by oxidation during cooking. The foods were easy to prepare and transport and they offered variety.

Mr. Charley and other speakers stressed the importance of easily prepared foods as a factor in family life, while others directed attention to their advantage in communal and emergency feeding. Mr. McLellan wanted more information broadcast as to simple methods for home-drying as an additional means of saving garden and allotment produce for the winter.

During the midday break a buffet lunch was served, and cooked dried foods manufactured by the improved processes described were sampled. Those present thus had an opportunity of confirming the claims made as regards their palatability.

\section{DIGESTIBILITY OF HIGH- EXTRACTION WHEATMEALS}

\section{By T. MORAN and J. PACE}

$T$

HE digestibility, in terms of energy, by human subjects of high-extraction meals $(80-100$ per cent extraction) is less than that of flour of 70 per cent or lower extraction. Recent work illustrating this is that of Macrae et al. ${ }^{1}$, who compared 73 per cent flour with wholemeal (100 per cent), and Krebs and Mellanby ${ }^{2}$, who compared 75 per cent flour with a sample of National wheatmeal (85 per cent). Unfortunately, there are no modern data on digestibility for meals between 85 per cent and 100 per cent. Older data exist ${ }^{3}$, and it is usually the practice to make the rate of extraction the basis for the comparison of the results of different investigators. In the accompanying figure, these data are plotted in this manner and the wide variation in the results is immediately apparent. In this article we wish to emphasize that in digestibility experiments or calculations on wheatmeals the practice of making the rate of extraction the basis of comparison is fundamentally unsound and may give rise to misleading results and deductions even though the experimental technique of the test meals, etc., is completely satisfactory. At a given extraction the digestibility must depend also on the composition of the wheat grist, the conditioning of the wheat and the method of milling.

The wheat grain consists of endosperm, germ, seed coat (testa, hyaline and aleurone layers) and the shell or pericarp. The layers of the seed coat and pericarp together, with a varying amount of endosperm, constitute the bran; without the endosperm they can be regarded as 'pure bran'.

There seems little doubt, especially in view of the work of Macrae et $a l .^{1}$ on wholemeal, that decrease in digestibility in passing from white flour to highextraction meals is due to the presence of bran or bran layers rich in indigestible fibrous material. The pericarp or beeswing* includes the layers which

* Beeswing is a general term used by millers and may comprise the whole or part of the pericarp. The actual composition depends on the condition of the wheat and the point of separation in the mill flow examination of one particular sample from the puriflers showed that it contained all four layers of the pericarp although the amounts of the two inner layers seemed to be slightly less in proportion. 